\title{
Direct versus indirect revascularization procedures for moyamoya disease: a comparative effectiveness study
}

\author{
Luke Macyszyn, MD, MA, Mark Attiah, MD, MS, MBE, Tracy S. Ma, MD, Zarina Ali, MD, \\ Ryan Faught, BA, Alisha Hossain, BA, Karen Man, BAS, Hiren Patel, BA, Rosanna Sobota, BA, \\ Eric L. Zager, MD, and Sherman C. Stein, MD
}

Department of Neurosurgery, Perelman School of Medicine, University of Pennsylvania, Philadelphia, Pennsylvania

\begin{abstract}
OBJECTIVE Moyamoya disease (MMD) is a chronic cerebrovascular disease that can lead to devastating neurological outcomes. Surgical intervention is the definitive treatment, with direct, indirect, and combined revascularization procedures currently employed by surgeons. The optimal surgical approach, however, remains unclear. In this decision analysis, the authors compared the effectiveness of revascularization procedures in both adult and pediatric patients with MMD.
\end{abstract}

METHODS A comprehensive literature search was performed for studies of MMD. Using complication and success rates from the literature, the authors constructed a decision analysis model for treatment using a direct and indirect revascularization technique. Utility values for the various outcomes and complications were extracted from the literature examining preferences in similar clinical conditions. Sensitivity analysis was performed.

RESULTS A structured literature search yielded 33 studies involving 4197 cases. Cases were divided into adult and pediatric populations. These were further subdivided into 3 different treatment groups: indirect, direct, and combined revascularization procedures. In the pediatric population at 5- and 10-year follow-up, there was no significant difference between indirect and combination procedures, but both were superior to direct revascularization. In adults at 4-year follow-up, indirect was superior to direct revascularization.

CONCLUSIONS In the absence of factors that dictate a specific approach, the present decision analysis suggests that direct revascularization procedures are inferior in terms of quality-adjusted life years in both adults at 4 years and children at 5 and 10 years postoperatively, respectively. These findings were statistically significant ( $p<0.001$ in all cases), suggesting that indirect and combination procedures may offer optimal results at long-term follow-up.

https://thejns.org/doi/abs/10.3171/2015.8.JNS15504

KEY WORDS moyamoya; revascularization; direct; indirect; decision analysis; vascular disorders

$\mathrm{M}$ OYAMOYA disease (MMD) is a rare, chronic disorder of unknown etiology defined by the gradual occlusion of intracranial vessels, beginning with the supraclinoid carotid arteries and progressing to the anterior, middle, and posterior cerebral arteries. As these vessels become occluded, small collaterals form at the base of the brain, which together give the appearance of a "puff of smoke" on angiographic studies. ${ }^{59,60}$ This disease, which is well documented in Asian populations, has a varying presentation depending on the age of the patient and classically manifests with intracerebral hemorrhage in adults and ischemic stroke in children. ${ }^{14}$ The natural history of this disease is also devastating, leading to recurring strokes and subsequent neurocognitive decline. ${ }^{2,4,41}$

The treatment prospects for an individual with MMD are limited because no known medical therapy has proven to be effective. 5,16 Surgical approaches have been developed to directly restore perfusion to oxygen-deprived areas of the brain or indirectly to enable collateral vessel formation. Surgical intervention has been demonstrated to reduce ischemic events and thus has become the only form of effective treatment in symptomatic MMD., ${ }^{5,22}$ 
Direct techniques, commonly involving a superficial temporal artery (STA) to middle cerebral artery (MCA) bypass, have been successfully used since the $1970 \mathrm{~s} .{ }^{48} \mathrm{Di}$ rect revascularization techniques are the most efficacious at reducing ischemic events. ${ }^{23,43}$ However, these techniques also have a myriad of drawbacks.

Direct revascularization carries the risk of hyperperfusion syndrome, which results from a sudden increase in cerebral blood flow; the incidence is as high as $28 \%$ and is seen most often in patients with extensive preoperative ischemia. ${ }^{11-13,23}$ Hyperperfusion syndrome can result in a temporary clinical picture that includes sensorimotor loss, aphasia, and dysarthria. ${ }^{48}$ Furthermore, direct procedures can accelerate stenosis of the internal carotid artery (ICA) as well the growth of moyamoya collaterals, which can lead to frontal lobe infarcts and cheiro-oral syndrome. ${ }^{20,40,54}$ Lastly, the procedure is challenging in the pediatric population because of the patients' smaller, more delicate cerebral vasculature. ${ }^{37}$

Indirect techniques rely on tissue supplied by the external carotid artery, which is placed on the brain surface and promotes angiogenesis. This approach generally requires less operative time since it is both technically less challenging and less invasive. ${ }^{64}$ Importantly, the indirect approaches do not require temporary occlusion of MCA branches, which is required in the STA-MCA bypass. As such, indirect approaches have a better safety profile than direct procedures and are preferred in children and adults with other medical comorbidities. ${ }^{4,9}$ However, in stark contrast to children, collaterals only form in approximately half of the adult patients following the indirect procedures. ${ }^{44}$ Even then, collaterals take months to mature, while the direct procedures provide robust reperfusion immediately. ${ }^{19,20,53}$ Immediate reperfusion can pose a risk of symptomatic hyperperfusion or postoperative hemorrhage in a chronically ischemic brain. Following indirect procedures, collaterals will only form in the area of the craniotomy field, and a field of insufficient size may lead to persistent frontal lobe ischemia. ${ }^{38}$

Combined procedures have also been employed by some surgeons who have postulated that the technique reduces the incidence of repeat bleeding; however, there is little evidence to show if the outcomes are actually improved or potentially worsened.29,39 Thus, the literature does not present a clearly superior revascularization technique in the surgical management of MMD. There have been no randomized clinical trials to facilitate comparison; furthermore, many studies to date combine adult and pediatric data when reporting outcomes.$^{58}$ Hence, in this report, we use a decision analytical model to compare clinical outcomes of direct, indirect, and combined revascularization techniques in pediatric and adult patients with MMD.

\section{Methods}

We developed a decision analytical model to compare clinical outcomes of direct and indirect revascularization techniques in pediatric and adult patients with MMD. The model projects quality-adjusted life years (QALYs) for the number of postoperative years for which adequate follow- up data are available. Data for the model were derived from a critical review of published reports.

\section{Management Strategies and Outcomes}

Direct revascularization involves STA-MCA (or other high-flow arterial) bypasses, whereas indirect bypasses involve placing tissue vascularized by extracranial vessels on the brain surface to promote revascularization. Indirect procedures include encephaloduroarteriosynangiosis, encephaloduroarteriomyosynangiosis, and pial synangiosis. Finally, combined approaches involve both direct and indirect procedures in the same patient.

Outcome is measured by surgery's impact on the patient's health-related quality of life (QOL). This is customarily measured as utility, a parametric $0-1$ scale of a given outcome's effect on QOL. These are patients' relative preferences for a given health outcome ${ }^{57}$ For example, an uneventful outcome (no perioperative complications or late-onset strokes) would be scored 1, and death would receive a score of 0 . Adverse outcomes would receive intermediate scores. To allow for the possibility that the rate of late strokes would increase with duration of follow-up, we employed QALYs, a combination of both quality and QOL. As an example, 5 years without operative or delayed complications would rate 5 QALYs as would 10 years during which the patient's QOL was 0.5. We assume that perioperative strokes influence utility for the entire followup, whereas late-onset strokes occur, on average, midway through the follow-up period.

\section{Decision Analytical Model}

Regardless of the surgery chosen, there may be perioperative complications, each with an impact on QOL. During follow-up, delayed ischemic stroke or intracranial hemorrhage may occur. For a given type of surgery, each pathway and outcome is dealt with in the model (Fig. 1). The probabilities and utilities of each outcome are calculated to arrive at an expected utility for each treatment option.

\section{Data Collection and Management}

We searched Medline, EMBASE, and the Cochrane Library for articles containing the key word "moyamoya" in conjunction with either the key word "therapy" or "surgery." We limited our search to articles published in English between 1990 and February 2013. All articles were reviewed by at least 2 authors. The search yielded 695 articles, of which 33 were used in the analysis. These series reported on 4197 surgeries. Reasons for article exclusion are summarized in Fig. 2. Separate searches were done to determine utilities associated with ischemic stroke and intracranial hemorrhage. Pediatric and adult (mean age $>$ 20 years) series were separated for the purpose of analysis. When more then one age group or surgical technique was reported in the same publication, we separated the groups. When this was impossible, the article was excluded from analysis. Table 1 summarizes the articles included in this study. In the absence of any controlled trials, all must be considered Class IV evidence. ${ }^{3}$ For both pediatric and adult groups, we separately recorded the following: numbers of sides operated upon in each series, mean ages, 


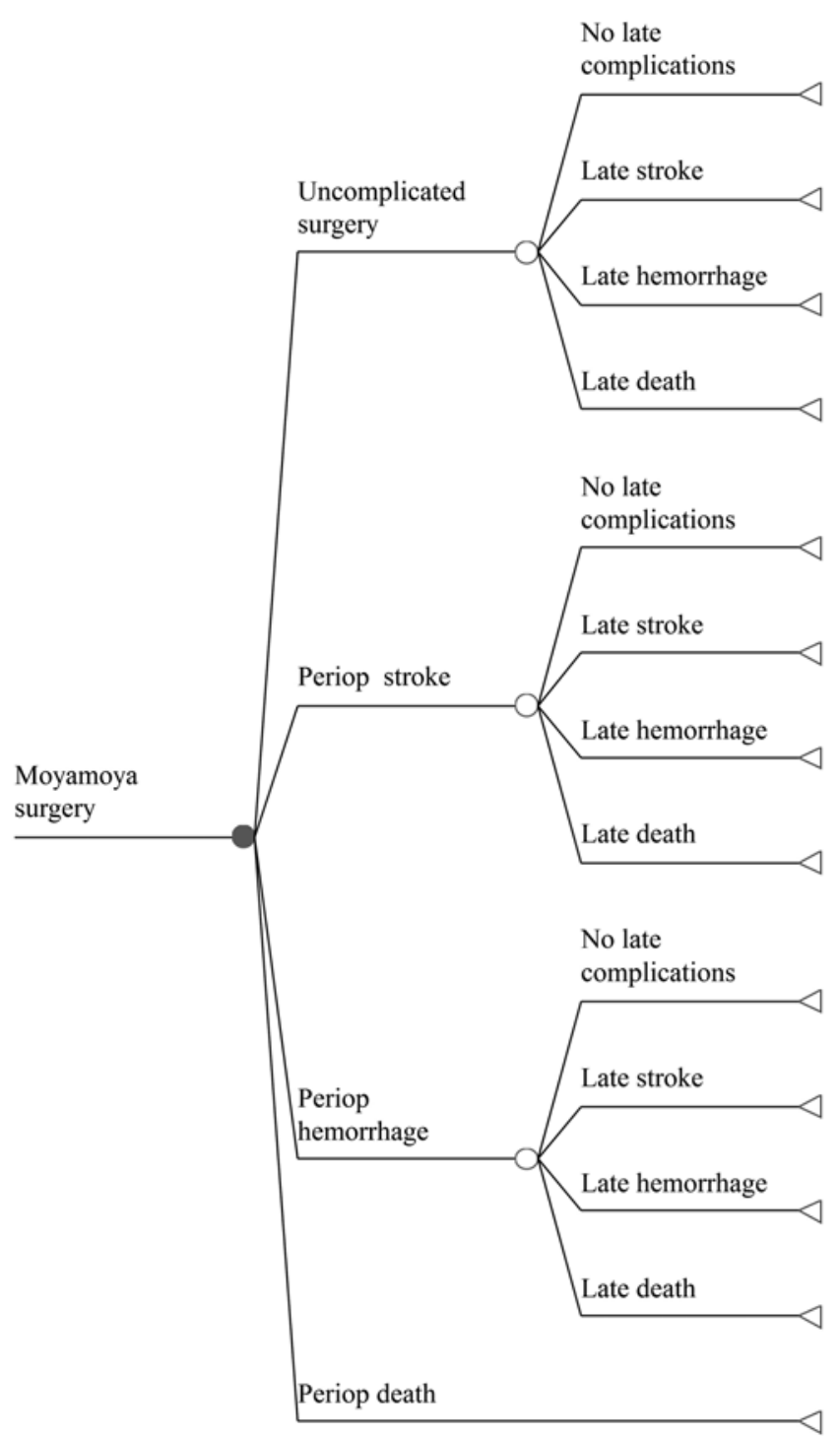

FIG. 1. Decision analytical tree outlining possible pathways and outcomes after surgery for MMD. After surgery, a patient can have an unremarkable recovery, or suffer perioperative stroke, intracranial hemorrhage, or even death. These same 4 possible outcomes can occur during follow-up.

sex distribution, perioperative complications and deaths, mean length of follow-up, late ischemic or hemorrhagic strokes or deaths. There was only a single report of combined revascularization in adults, so this category was omitted from the analysis. The patient population did not undergo subgroup analysis for Caucasian and Asian populations due to low numbers in relevant studies.

\section{Statistical Analysis}

Probabilities report the likelihood that a hypothetical patient travels along a particular pathway picture in Fig. 1. These represent point estimates of pooled data, which were determined via meta-analysis. ${ }^{10}$ After testing to exclude heterogeneity, ${ }^{36}$ an inverse-variance-weighted random-effects model was used to calculate means and distributions. Demographic data, such as mean ages and
TABLE 1. Articles used in the analysis

\begin{tabular}{|c|c|c|c|}
\hline Authors \& Year & Age Group & $\begin{array}{c}\text { Bypass } \\
\text { Technique }\end{array}$ & $\begin{array}{l}\text { No. of } \\
\text { Cases }\end{array}$ \\
\hline Adelson \& Scott, 1995 & Pediatric & Indirect & 34 \\
\hline \multirow[t]{2}{*}{ Choi et al., 1997} & Pediatric & Direct & 56 \\
\hline & Pediatric & Indirect & 56 \\
\hline \multirow[t]{3}{*}{ Darwish \& Besser, 2005} & Pediatric & Direct & 7 \\
\hline & Pediatric & Indirect & 10 \\
\hline & Pediatric & Combined & 5 \\
\hline \multirow[t]{2}{*}{ Duan et al., 2012} & Adult & Direct & 45 \\
\hline & Adult & Indirect & 1229 \\
\hline Fujimura et al., 2008 & Pediatric & Combined & 17 \\
\hline Hankinson et al., 2008 & Pediatric & Indirect & 12 \\
\hline Hirotsune et al., 1997 & Pediatric & Indirect & 13 \\
\hline Hyun et al., 2010 & Adult & Indirect & 228 \\
\hline \multirow[t]{2}{*}{ Ishikawa et al., 1997} & Pediatric & Indirect & 5 \\
\hline & Pediatric & Combined & 62 \\
\hline \multirow[t]{2}{*}{ Ishikawa et al., 2006} & Adult & Combined & 11 \\
\hline & Pediatric & Combined & 15 \\
\hline Isono et al., 2002 & Pediatric & Indirect & 22 \\
\hline Jea et al., 2005 & Pediatric & Indirect & 28 \\
\hline Karasawa et al., 1992 & Pediatric & Combined & 104 \\
\hline Kashiwagi et al., 1997 & Pediatric & Indirect & 25 \\
\hline Khan et al., 2012 & Adult & Direct & 717 \\
\hline Kim et al., 2000 & Pediatric & Indirect & 171 \\
\hline Kim et al., 2002 & Pediatric & Indirect & 92 \\
\hline Kim et al., 2003 & Pediatric & Indirect & 134 \\
\hline \multirow[t]{2}{*}{ Kim et al., 2007} & Pediatric & Indirect & 16 \\
\hline & Pediatric & Combined & 7 \\
\hline Kim et al., 2010 & Pediatric & Indirect & 410 \\
\hline Mukawa et al., 2012 & Pediatric & Indirect & 172 \\
\hline Nagata et al., 2006 & Pediatric & Indirect & 15 \\
\hline Ohtaki et al., 1998 & Pediatric & Combined & 16 \\
\hline Park et al., 2007 & Pediatric & Indirect & 34 \\
\hline Phi et al., 2011 & Pediatric & Indirect & 65 \\
\hline Robertson et al., 1997 & Pediatric & Indirect & 25 \\
\hline Sainte-Rose et al., 2006 & Pediatric & Indirect & 25 \\
\hline Sakamoto et al., 1997 & Pediatric & Combined & 19 \\
\hline Scott et al., 2004 & Pediatric & Indirect & 126 \\
\hline Song et al., 2012 & Pediatric & Indirect & 36 \\
\hline Starke et al., 2009 & Adult & Indirect & 67 \\
\hline \multirow[t]{2}{*}{ Touho, 2007} & Pediatric & Direct & 53 \\
\hline & Pediatric & Combined & 13 \\
\hline
\end{tabular}

sex distributions, were pooled in the same fashion. We tested the hypothesis that late stroke and hemorrhage rates were linearly related to length of follow-up. For this, we employed an inverse-variance-weighted random-effects model of meta-regression. These data were used to calculate expected QALYs associated with each of the 3 surgical options. Sensitivity analysis used beta distributions for probabilities, normal distribution for utilities, and a 2D Monte Carlo simulation (100 trials, each made up of 100 


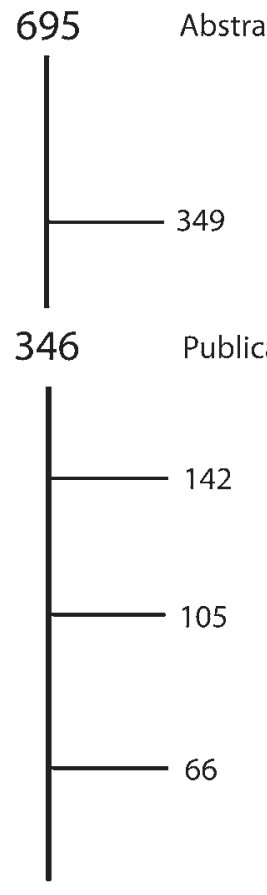

Abstracts rejected

33 Articles used for this report

FIG. 2. Summary of the structured literature review showing numbers of abstracts reviewed, articles read, those used in our analysis, and reasons for rejection.

microsimulations). ${ }^{6}$ Meta-analytical pooling and metaregressions were done with Stata (version 12.1, StataCorp LP). Analyses of the model employed TreeAge Pro 2012 (Tree Age Software, Inc.). Statistical comparisons employed one-way ANOVA; pairwise comparisons used the Bonferroni correction for multiple comparisons. We considered differences whose $\mathrm{p}<0.05$ to be significant.

\section{Results}

The utility of a generic ischemic stroke is $0.599 \pm$ $0.364:{ }^{15}$ that of intracranial hemorrhage is $0.868 \pm 0.169 .{ }^{42}$

\section{Pediatric MMD}

Table 2 presents mean ages and sex distributions for the 3 pediatric surgical cohorts. There were no significant differences among the 3 groups, nor were there any significant differences between any 2 pairs.
Pooled values of probabilities for the model are presented in Table 3. Meta-regression showed no significant increased rate of stroke or hemorrhage with length of follow-up. Accordingly, the pooled values of these parameters were used. So few studies reported mortality rates during follow-up that this aspect was excluded from the analysis. It is expected that perfect treatment, without perioperative or late complications, would result in a number of QALYs equal to the length of the follow-up.

The model calculated the expected QALYs in the 3 pediatric groups after 5- and 10-year follow-up periods (Table 4). These differences were highly significant $(\mathrm{F}=$ $209.04, p<0.001)$. Although there is no significant difference between the combined and indirect approaches at 5 or 10 years $(p=0.383$ and $p=0.261$, respectively), both were superior to direct revascularization ( $\mathrm{p}<0.001)$.

\section{Adult MMD}

Table 2 also presents mean ages and sex distributions for the 2 adult surgical cohorts. The Student t-test shows no significant differences between the groups. Pooled values of probabilities for the model are presented in Table 3. As in the case of children, meta-regression showed no significant increased rate of stroke or hemorrhage with length of follow-up. We used pooled values here as well. Late death occurred in $0.8 \%( \pm 0.01)$ of adults.

Because so few reports involved follow-up exceeding 4 years postsurgery, we compared procedures at that point. Table 4 shows that indirect revascularization resulted in over one-half QALY more than the direct option during the 4-year follow-up period. This difference was highly significant $(\mathrm{p}<0.001)$.

\section{Discussion}

In this study, we applied decision analysis methodology to compare the effectiveness of surgical revascularization techniques to treat MMD. To date, there have been no clinical trials comparing surgical revascularization techniques for MMD. Were an adequately powered, well-run, randomized, controlled trial practical, it would be preferable to a comparative effectiveness study such as ours. However, the large numbers of subjects needed, the lack of clinical equipoise among neurosurgeons, the great variety of surgical techniques, and clinical presentation in MMD make such a trial very unlikely. Thus, our results currently offer the best comparison of the two approaches. The present study shows that in pediat-

TABLE 2. Average ages and proportion of females in surgical groups

\begin{tabular}{ccccccc}
\hline Age Group & Mean Age & SD & Difference & Proportion Female & SD & Difference \\
\hline Children & & & & & & \\
\hline Direct & 10.037 & 4.868 & $F=1.888, p=0.168$ & 0.579 & 0.198 & $F=1.003, p=0.379$ \\
\hline Indirect & 8.599 & 1.965 & & 0.589 & 0.067 & \\
\hline Combined & 7.439 & 1.264 & & 0.641 & 0.119 & \\
\hline Adults & & & & & & \\
\hline Direct & 29.7 & 2.020 & $p=0.334$ & 0.607 & 0.151 & $p=0.914$ \\
\hline Indirect & 34.7 & 6.362 & & 0.624 & 0.1544 & \\
\hline
\end{tabular}


TABLE 3. Pooled values of probabilities for the model

\begin{tabular}{|c|c|c|c|c|c|c|c|c|c|c|}
\hline \multirow[b]{3}{*}{ Age Group } & \multicolumn{6}{|c|}{ Perioperative Complication } & \multicolumn{4}{|c|}{ Late Complication } \\
\hline & \multicolumn{2}{|c|}{ Mortality } & \multicolumn{2}{|c|}{ Ischemic Stroke } & \multicolumn{2}{|c|}{ Intracranial Hemorrhage } & \multicolumn{2}{|c|}{ Ischemic Stroke } & \multicolumn{2}{|c|}{ Intracranial Hemorrhage } \\
\hline & Mean & SD & Mean & SD & Mean & SD & Mean & SD & Mean & SD \\
\hline \multicolumn{11}{|l|}{ Children } \\
\hline Direct & 0 & 0 & 0.096 & 0.042 & 0.018 & 0.004 & 0.478 & 0.463 & 0.119 & 0.218 \\
\hline Indirect & 0.010 & 0.009 & 0.090 & 0.078 & 0.029 & 0.057 & 0.115 & 0.064 & 0.080 & 0.061 \\
\hline Combined & 0.010 & 0.003 & 0.058 & 0.053 & 0 & 0 & 0.158 & 0.097 & 0.046 & 0.032 \\
\hline \multicolumn{11}{|l|}{ Adults } \\
\hline Direct & 0.011 & 0.003 & 0.037 & 0.039 & 0.017 & 0.003 & 0.014 & 0.047 & 0.018 & 0.033 \\
\hline Indirect & 0 & 0 & 0.050 & 0.029 & 0.001 & 0.000 & 0.105 & 0.080 & 0.016 & 0.0002 \\
\hline
\end{tabular}

ric patients, there was no significant difference between the combined and indirect approaches, but both are superior to direct revascularization at 5- and 10-year followup periods. In adults, indirect revascularization yielded $50 \%$ more QALYs than the direct approach at the 4-year follow-up point.

This apparent superiority of indirect procedures may be due to the sheer technical difficulty of the direct procedures and the learning curves associated with performing them well. Though direct procedures may be more effective in reducing the incidence of future stroke, the added risk of the procedure's technical difficulty (especially in children), hyperperfusion syndrome, and increasing the rate of stenosis appear to outweigh this benefit. The reduced operative time and invasiveness, as well as the relative ease of the indirect procedures, may contribute to the well-documented decrease in adverse effects. Moreover, it is also possible that the risk of perioperative stroke from the delayed formation of collaterals following indirect procedures may be overstated. It is also important to note that appropriate propensity matching is not possible given that the patient populations may differ.

Our study noted that pediatric patients tolerated the combined procedure well and did not suffer from an increased rate of adverse events as compared with adult patients undergoing the direct procedure. However, the current study is a review rather than a study designed to test noninferiority. It would be necessary to conduct further analysis to compare the indirect and combined procedure in the pediatric population to determine truly if the outcomes were similar. If the two procedures were determined to have equal efficacy, it stands to reason that the choice would be the less invasive approach.

Our decision model is limited by its simplifying as- sumptions. Our small numbers precluded us from confirming that the incidence of late-onset postoperative ischemic stroke increases over time. Additionally, particular surgeons are certainly more facile at direct anastomoses than others, and certain indirect procedures may well be superior to others. The model developed in the present study cannot make allowances for this. Furthermore, we limited surgical complications to ischemic stroke and intracranial hemorrhage. However, it should be noted that other recorded complications tended to be transient or mild with little effect on overall outcome.

An important limitation in a retrospective analysis such as this is the unknown, potentially confounding factors that influenced selections of surgical approach in the studies that were analyzed and used to create our decision model. Hence, we were unable to control for various vascular factors that might have influenced a surgeon's decision making, and likewise, we could not ensure that these factors were the same among the various studies reviewed. This may have introduced selection bias and thus have restricted the validity of our results. Finally, many studies of outcome after revascularization have only focused on ischemic events, whereas other adverse outcomes such as seizures and neurocognitive decline are also critical considerations. ${ }^{63}$

\section{Conclusions}

We performed a comparative analysis of direct, indirect, and combined revascularization techniques for MMD in adults and children. In both patient populations, we found significantly inferior outcomes with direct revascularization compared with the other two surgical approaches.

TABLE 4. Comparison of expected QALYs in children and adults

\begin{tabular}{|c|c|c|c|c|c|c|}
\hline \multirow[b]{3}{*}{ Surgical Strategy } & \multicolumn{6}{|c|}{ Follow-Up Durations } \\
\hline & \multicolumn{2}{|c|}{ Children, 5 Yrs } & \multicolumn{2}{|c|}{ Children, 10 Yrs } & \multicolumn{2}{|c|}{ Adults, 4 Yrs } \\
\hline & Mean & SD & Mean & SD & Mean & SD \\
\hline Direct & 4.0560 & 0.1253 & 8.1177 & 0.1710 & 3.502 & 0.081 \\
\hline Indirect & 4.3143 & 0.1274 & 8.6523 & 0.1954 & 3.553 & 0.059 \\
\hline Combined & 4.3461 & 0.1222 & 8.7090 & 0.1986 & NA & NA \\
\hline
\end{tabular}

$\mathrm{NA}=$ not analyzed (inadequate data). 


\section{References}

1. Adelson PD, Scott RM: Pial synangiosis for moyamoya syndrome in children. Pediatr Neurosurg 23:26-33, 1995

2. Bruno A, Adams HP Jr, Biller J, Rezai K, Cornell S, Aschenbrener CA: Cerebral infarction due to moyamoya disease in young adults. Stroke 19:826-833, 1988

3. Centre for Evidence-Based Medicine: Levels of evidence (March 2009). Oxford Centre for Evidence-Based Medicine. (http://www.cebm.net/oxford-centre-evidencebased-medicine-levels-evidence-march-2009) (Accessed June 16, 2016)

4. Chiu D, Shedden P, Bratina P, Grotta JC: Clinical features of moyamoya disease in the United States. Stroke 29:13471351, 1998

5. Choi JU, Kim DS, Kim EY, Lee KC: Natural history of moyamoya disease: comparison of activity of daily living in surgery and non surgery groups. Clin Neurol Neurosurg 99 (Suppl 2):S11-S18, 1997

6. Concato J, Feinstein AR: Monte Carlo methods in clinical research: applications in multivariable analysis. J Investig Med 45:394-400, 1997

7. Darwish B, Besser M: Long term outcome in children with moyamoya disease: experience with 16 patients. J Clin Neurosci 12:873-877, 2005

8. Duan L, Bao XY, Yang WZ, Shi WC, Li DS, Zhang ZS, et al: Moyamoya disease in China: its clinical features and outcomes. Stroke 43:56-60, 2012

9. Dusick JR, Gonzalez NR, Martin NA: Clinical and angiographic outcomes from indirect revascularization surgery for moyamoya disease in adults and children: a review of 63 procedures. Neurosurgery 68:34-43, 2011

10. Einarson TR: Pharmacoeconomic applications of metaanalysis for single groups using antifungal onychomycosis lacquers as an example. Clin Ther 19:559-569, 538-539, 1997

11. Fujimura M, Kaneta T, Mugikura S, Shimizu H, Tominaga $\mathrm{T}$ : Temporary neurologic deterioration due to cerebral hyperperfusion after superficial temporal artery-middle cerebral artery anastomosis in patients with adult-onset moyamoya disease. Surg Neurol 67:273-282, 2007

12. Fujimura M, Kaneta T, Tominaga T: Efficacy of superficial temporal artery-middle cerebral artery anastomosis with routine postoperative cerebral blood flow measurement during the acute stage in childhood moyamoya disease. Childs Nerv Syst 24:827-832, 2008

13. Fujimura M, Mugikura S, Kaneta T, Shimizu H, Tominaga T: Incidence and risk factors for symptomatic cerebral hyperperfusion after superficial temporal artery-middle cerebral artery anastomosis in patients with moyamoya disease. Surg Neurol 71:442-447, 2009

14. Fukui M, Kono S, Sueishi K, Ikezaki K: Moyamoya disease. Neuropathology 20 Suppl:S61-S64, 2000

15. Ghatnekar O, Eriksson M, Glader EL: Mapping health outcome measures from a stroke registry to EQ-5D weights. Health Qual Life Outcomes 11:34, 2013

16. Hallemeier CL, Rich KM, Grubb RL Jr, Chicoine MR, Moran CJ, Cross DT III, et al: Clinical features and outcome in North American adults with moyamoya phenomenon. Stroke 37:1490-1496, 2006

17. Hankinson TC, Bohman LE, Heyer G, Licursi M, Ghatan S, Feldstein NA, et al: Surgical treatment of moyamoya syndrome in patients with sickle cell anemia: outcome following encephaloduroarteriosynangiosis. J Neurosurg Pediatr 1:211-216, 2008

18. Hirotsune N, Meguro T, Kawada S, Nakashima H, Ohmoto T: Long-term follow-up study of patients with unilateral moyamoya disease. Clin Neurol Neurosurg 99 (Suppl 2):S178S181, 1997

19. Houkin K, Kuroda S, Ishikawa T, Abe H: Neovascularization (angiogenesis) after revascularization in moyamoya disease. Which technique is most useful for moyamoya disease? Acta Neurochir (Wien) 142:269-276, 2000

20. Houkin K, Nakayama N, Kuroda S, Ishikawa T, Nonaka T: How does angiogenesis develop in pediatric moyamoya disease after surgery? A prospective study with MR angiography. Childs Nerv Syst 20:734-741, 2004

21. Hyun SJ, Kim JS, Hong SC: Prognostic factors associated with perioperative ischemic complications in adult-onset moyamoya disease. Acta Neurochir (Wien) 152:1181-1188, 2010

22. Ikezaki K, Fukui M, Inamura T, Kinukawa N, Wakai K, Ono Y: The current status of the treatment for hemorrhagic type moyamoya disease based on a 1995 nationwide survey in Japan. Clin Neurol Neurosurg 99 (Suppl 2):S183-S186, 1997

23. Ishikawa T, Houkin K, Kamiyama H, Abe H: Effects of surgical revascularization on outcome of patients with pediatric moyamoya disease. Stroke 28:1170-1173, 1997

24. Ishikawa T, Kamiyama H, Kuroda S, Yasuda H, Nakayama N, Takizawa K: Simultaneous superficial temporal artery to middle cerebral or anterior cerebral artery bypass with pansynangiosis for Moyamoya disease covering both anterior and middle cerebral artery territories. Neurol Med Chir (Tokyo) 46:462-468, 2006

25. Isono M, Ishii K, Kamida T, Inoue R, Fujiki M, Kobayashi H: Long-term outcomes of pediatric moyamoya disease treated by encephalo-duro-arterio-synangiosis. Pediatr Neurosurg 36:14-21, 2002

26. Jea A, Smith ER, Robertson R, Scott RM: Moyamoya syndrome associated with Down syndrome: outcome after surgical revascularization. Pediatrics 116:e694-e701, 2005

27. Karasawa J, Touho H, Ohnishi H, Miyamoto S, Kikuchi H: Long-term follow-up study after extracranial-intracranial bypass surgery for anterior circulation ischemia in childhood moyamoya disease. J Neurosurg 77:84-89, 1992

28. Kashiwagi S, Kato S, Yamashita K, Takasago T, Akimura T, Okamura S, et al: Revascularization with split duro-encephalo-synangiosis in the pediatric moyamoya disease-surgical result and clinical outcome. Clin Neurol Neurosurg 99 (Suppl 2):S115-S117, 1997

29. Kawaguchi S, Okuno S, Sakaki T: Effect of direct arterial bypass on the prevention of future stroke in patients with the hemorrhagic variety of moyamoya disease. J Neurosurg 93:397-401, 2000

30. Khan N, Achrol AS, Guzman R, Burns TC, Dodd R, BellStephens T, et al: Sex differences in clinical presentation and treatment outcomes in Moyamoya disease. Neurosurgery 71:587-593, 2012

31. Kim CY, Wang KC, Kim SK, Chung YN, Kim HS, Cho BK: Encephaloduroarteriosynangiosis with bifrontal encephalogaleo(periosteal)synangiosis in the pediatric moyamoya disease: the surgical technique and its outcomes. Childs Nerv Syst 19:316-324, 2003

32. Kim DS, Kang SG, Yoo DS, Huh PW, Cho KS, Park CK: Surgical results in pediatric moyamoya disease: angiographic revascularization and the clinical results. Clin Neurol Neurosurg 109:125-131, 2007

33. Kim SK, Cho BK, Phi JH, Lee JY, Chae JH, Kim KJ, et al: Pediatric moyamoya disease: An analysis of 410 consecutive cases. Ann Neurol 68:92-101, 2010

34. Kim SK, Wang KC, Kim DG, Paek SH, Chung HT, Han $\mathrm{MH}$, et al: Clinical feature and outcome of pediatric cerebrovascular disease: a neurosurgical series. Childs Nerv Syst 16:421-428, 2000

35. Kim SK, Wang KC, Kim IO, Lee DS, Cho BK: Combined encephaloduroarteriosynangiosis and bifrontal encephalogaleo(periosteal)synangiosis in pediatric moyamoya disease. Neurosurgery 50:88-96, 2002

36. King JT Jr, Berlin JA, Flamm ES: Morbidity and mortality 
from elective surgery for asymptomatic, unruptured, intracranial aneurysms: a meta-analysis. J Neurosurg 81:837-842, 1994

37. Kuroda S, Houkin K: Bypass surgery for moyamoya disease: concept and essence of surgical techniques. Neurol Med Chir (Tokyo) 52:287-294, 2012

38. Kuroda S, Houkin K, Ishikawa T, Nakayama N, Ikeda J, Ishii $\mathrm{N}$, et al: Determinants of intellectual outcome after surgical revascularization in pediatric moyamoya disease: a multivariate analysis. Childs Nerv Syst 20:302-308, 2004

39. Kuroda S, Houkin K, Ishikawa T, Nakayama N, Iwasaki Y: Novel bypass surgery for moyamoya disease using pericranial flap: its impacts on cerebral hemodynamics and long-term outcome. Neurosurgery 66:1093-1101, 2010

40. Kuroda S, Houkin K, Nunomura M, Abe H: Frontal lobe infarction due to hemodynamic change after surgical revascularization in moyamoya disease-two case reports. Neurol Med Chir (Tokyo) 40:315-320, 2000

41. Kurokawa T, Tomita S, Ueda K, Narazaki O, Hanai T, Hasuo $\mathrm{K}$, et al: Prognosis of occlusive disease of the circle of Willis (moyamoya disease) in children. Pediatr Neurol 1:274-277, 1985

42. Lega BC, Danish SF, Malhotra NR, Sonnad SS, Stein SC: Choosing the best operation for chronic subdural hematoma: a decision analysis. J Neurosurg 113:615-621, 2010

43. Miyamoto S, Akiyama Y, Nagata I, Karasawa J, Nozaki K, Hashimoto N, et al: Long-term outcome after STA-MCA anastomosis for moyamoya disease. Neurosurg Focus 5(5):e5, 1998

44. Mizoi K, Kayama T, Yoshimoto T, Nagamine Y: Indirect revascularization for moyamoya disease: is there a beneficial effect for adult patients? Surg Neurol 45:541-549, 1996

45. Mukawa M, Nariai T, Matsushima Y, Tanaka Y, Inaji M, Maehara T, et al: Long-term follow-up of surgically treated juvenile patients with moyamoya disease. J Neurosurg Pediatr 10:451-456, 2012

46. Nagata S, Matsushima T, Morioka T, Matsukado K, Mihara F, Sasaki T, et al: Unilaterally symptomatic moyamoya disease in children: long-term follow-up of 20 patients. Neurosurgery 59:830-837, 2006

47. Ohtaki M, Uede T, Morimoto S, Nonaka T, Tanabe S, Hashi $\mathrm{K}$ : Intellectual functions and regional cerebral haemodynamics after extensive omental transplantation spread over both frontal lobes in childhood moyamoya disease. Acta Neurochir (Wien) 140:1043-1053, 1998

48. Pandey P, Steinberg GK: Neurosurgical advances in the treatment of moyamoya disease. Stroke 42:3304-3310, 2011

49. Park JH, Yang SY, Chung YN, Kim JE, Kim SK, Han DH, et al: Modified encephaloduroarteriosynangiosis with bifrontal encephalogaleoperiosteal synangiosis for the treatment of pediatric moyamoya disease. Technical note. J Neurosurg 106 (3 Suppl):237-242, 2007

50. Phi JH, Wang KC, Cho BK, Lee MS, Lee JH, Yu KS, et al: Long-term social outcome in children with moyamoya disease who have reached adulthood. J Neurosurg Pediatr 8:303-309, 2011

51. Robertson RL, Burrows PE, Barnes PD, Robson CD, Poussaint TY, Scott RM: Angiographic changes after pial synangiosis in childhood moyamoya disease. AJNR Am J Neuroradiol 18:837-845, 1997

52. Sainte-Rose C, Oliveira R, Puget S, Beni-Adani L, Boddaert $\mathrm{N}$, Thorne J, et al: Multiple bur hole surgery for the treatment of moyamoya disease in children. J Neurosurg 105 (6 Suppl):437-443, 2006

53. Sakamoto T, Kawaguchi M, Kurehara K, Kitaguchi K, Furuya $\mathrm{H}$, Karasawa J: Risk factors for neurologic deterioration after revascularization surgery in patients with moyamoya disease. Anesth Analg 85:1060-1065, 1997

54. Sasamori T, Kuroda S, Nakayama N, Iwasaki Y: Incidence and pathogenesis of transient cheiro-oral syndrome after surgical revascularization for moyamoya disease. Neurosurgery 67:1054-1060, 2010

55. Scott RM, Smith JL, Robertson RL, Madsen JR, Soriano SG, Rockoff MA: Long-term outcome in children with moyamoya syndrome after cranial revascularization by pial synangiosis. J Neurosurg 100 (2 Suppl Pediatrics):142-149, 2004

56. Song YS, Oh SW, Kim YK, Kim SK, Wang KC, Lee DS: Hemodynamic improvement of anterior cerebral artery territory perfusion induced by bifrontal encephalo(periosteal) synangiosis in pediatric patients with moyamoya disease: a study with brain perfusion SPECT. Ann Nucl Med 26:47-57, 2012

57. Sox HC, Blatt MA, Higgings MC, Marton KI: Medical Decision Making. Philadelphia: American College of Physicians Press, 2007

58. Starke RM, Komotar RJ, Connolly ES: Optimal surgical treatment for moyamoya disease in adults: direct versus indirect bypass. Neurosurg Focus 26(4):E8, 2009

59. Suzuki J, Kodama N: Moyamoya disease-a review. Stroke 14:104-109, 1983

60. Suzuki J, Takaku A: Cerebrovascular "moyamoya" disease. Disease showing abnormal net-like vessels in base of brain. Arch Neurol 20:288-299, 1969

61. Touho H: Subcutaneous tissue graft including a scalp artery and a relevant vein for the treatment of cerebral ischemia in childhood moyamoya disease. Surg Neurol 68:639-645, 2007

62. Veeravagu A, Guzman R, Patil CG, Hou LC, Lee M, Steinberg GK: Moyamoya disease in pediatric patients: outcomes of neurosurgical interventions. Neurosurg Focus 24(2):E16, 2008

63. Zalonis I, Christidi F, Kararizou E, Triantafyllou NI, Spengos K, Vassilopoulos D: Cognitive deficits presenting as psychiatric symptoms in a patient with moyamoya disease. Psychol Rep 107:727-732, 2010

64. Zipfel GJ, Fox DJ Jr, Rivet DJ: Moyamoya disease in adults: the role of cerebral revascularization. Skull Base 15:27-41, 2005

\section{Disclosures}

The authors report no conflict of interest concerning the materials or methods used in this study or the findings specified in this paper.

\section{Author Contributions}

Conception and design: Stein, Macyszyn, Ali. Acquisition of data: Macyszyn, Attiah, Faught, Hossain, Man, Patel, Sobota. Analysis and interpretation of data: Macyszyn, Ali. Drafting the article: Macyszyn, Attiah, Ali, Zager. Critically revising the article: Stein, Macyszyn, Ali, Zager. Reviewed submitted version of manuscript: Stein, Macyszyn, Ma, Ali. Approved the final version of the manuscript on behalf of all authors: Stein. Statistical analysis: Macyszyn, Ali. Administrative/technical/material support: Stein, Macyszyn, Attiah. Study supervision: Stein, Macyszyn, Zager.

\section{Correspondence}

Sherman C. Stein, Department of Neurosurgery, University of Pennsylvania, 3400 Spruce St., 3 Silverstein Pavilion, Philadelphia, PA 19106. email: sherman.stein@uphs.upenn.edu. 